\title{
Positive surgical margins during partial nephrectomy for renal cell carcinoma: Results from Canadian Kidney Cancer information system (CKCis) collaborative
}

\author{
Rahul K. Bansal, MD, MS, MCh'; Simon Tanguay, MD2; Antonio Finelli, MD'; Ricardo Rendon, MD'; \\ Ronald B. Moore, MD, PhD; Rodney H. Breau, MD'; Louis Lacombe, MD'; Peter C. Black, MD;

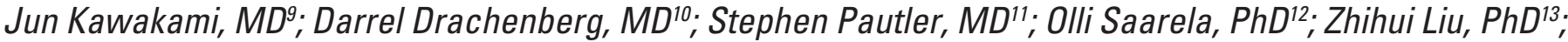 \\ Michael A.S. Jewett, $M D^{3}$; Anil Kapoor, $M D^{14}$
}

\begin{abstract}
'Division of Urology, McMaster University, Hamilton, ON; 2 2Division of Urology, McGill University, Montreal, QC; ${ }^{3}$ Division of Urology, Departments of Surgery and Surgical Oncology, Princess Margaret Cancer Centre, University Health Network and the University of Toronto, Toronto, ON; ${ }^{4}$ Department of Urology, Queen Elizabeth II Health Sciences Centre, Dalhousie University, Halifax, NS; ${ }^{5}$ Division of Urology, University of Alberta, Edmonton, AB; ${ }^{6}$ Ottawa Hospital Research Institute, Ottawa, ON; ${ }^{7}$ Division of Urology, Université Laval, Quebec, QC; ${ }^{8}$ Department of Urology, University of British Columbia, Vancouver, BC; '9Southern Alberta Institute of Urology, University of Calgary, Calgary, AB; ${ }^{10 S}$ Section of Urology, Department of Surgery, University of Manitoba, Winnipeg, MB; "'Divisions of Urology and Surgical Oncology, Departments of Surgery and Oncology, Western University, London, ON; ${ }^{22}$ Dalla Lana School of Public Health, University of Toronto, Toronto, ON; ${ }^{13}$ Cancer Care Ontario, Toronto, ON; ${ }^{14}$ Division of Urology, McMaster University, Hamilton, ON; Canada
\end{abstract}

Cite as: Can Urol Assoc J 2017;11 (6):182-7. htrp://dx.doi.org/10.5489/cuaj.4264

\section{Abstract}

Introduction: We sought to determine the incidence, risk factors, and prognosis for patients with positive surgical margin (PSM) during partial nephrectomy (PN) for renal cell carcinoma (RCC).

Methods: From the Canadian Kidney Cancer information system (CKCis) database, a historical cohort of PN patients with PSM were identified and compared to negative surgical margin (NSM). Risk factors for PSM were examined through multivariable logistic regression. Kaplan-Meier curves were used to compare progression-free survival.

Results: Of 1103 patients, 972 (88.1\%), 71 (6.4\%), and 60 (5.4\%) had NSM, PSM, and unknown status, respectively. Median patient age and tumour size were 61 years and $3.0 \mathrm{~cm}$ for both groups. From multivariable analysis, pathological stage $\geq \mathrm{T} 3$ (odds ratio [OR] 2.51; 95\% confidence interval [CI] 1.13-5.60) and Fuhrman grade 4 (OR 5.35; 95\% Cl 1.11-25.72) were associated with PSM, whereas age, operative technique, and tumour size were not. Forty-nine $(5.0 \%)$ patients from the NSM cohort and seven $(9.9 \%)$ from the PSM cohort had a local/systemic progression of disease (adjusted hazard ratio [HR] 1.4; 95\% Cl 0.6-3.6). There were three $(0.3 \%)$ cancer-related deaths in the NSM group and none in the PSM group. After median followup of 19 (interquartile range [IQR] 5-42) and 15 (IQR 7-30) months, 855 (91.4\%) and 61 (89.7\%) patients were alive in the NSM and PSM groups, respectively.

Conclusions: PSM occurred in $6.4 \%$ of PNs performed for RCC in this pan-Canadian cohort. Higher stage and grade are associated with a higher risk of positive margin. The small association between a PSM and progression suggests that complete nephrectomy is not necessary in patients with a PSM. The main study limitations are lack of nephrometry score and possible reporting bias.

\section{Introduction}

The incidence of renal cell carcinoma (RCC) has increased by about $2 \%$ annually over the last couple of decades. ${ }^{1,2}$ Combined data from National Program of Cancer Registries and Surveillance Epidemiology and End Results shows a $4.3 \%$ annual increase in incidence of localized RCC from 2001-2010. ${ }^{2}$ The increase in tumour detection seems to be mainly due to incidental detection of asymptomatic small renal masses with the use of abdominal ultrasonography and computerized tomography. ${ }^{3}$ The current standard of treatment for small renal mass is partial nephrectomy $(\mathrm{PN})$ whenever technically feasible. ${ }^{4}$ In multiple studies, PN for low-stage renal tumours has shown comparable long-term cancerspecific outcomes as compared to radical nephrectomy. . $^{5-8}$

The objective during $\mathrm{PN}$ is to completely remove the tumour while preserving normal renal parenchyma. When the resected tumour is inspected histologically, malignant cells are sometimes present at the edge of resection; this is termed a positive surgical margin (PSM). The incidence of PSM ranges from $0-10 \%$ in published studies. ${ }^{9-12}$ The optimal management of patients who have a PSM during PN is unclear. Some have performed an immediate or delayed complete (radical) nephrectomy in patients with a PSM. In these studies, there has been a low yield of residual tumour in the remaining kidney or on re-resection of the PN bed. ${ }^{13-15}$ Other groups have not performed a complete nephrectomy and followed patients. In some studies, disease-specific and overall survival rates were similar between patients with and without a PSM. ${ }^{9-11}$ In others, PSM was associated with significantly higher recurrence and metastasis compared to patients with negative surgical margin (NSM). ${ }^{16}$ Given con- 
flicting evidence from previous studies, the ideal management of patients with PSM following PN is unclear.

The purpose of this study was to determine the incidence and risk factors for a PSM during PN. We also aimed to compare the risk of cancer progression (recurrence/metastasis) between patients with PSM and NSM.

\section{Methods}

\section{Patients}

We performed a historical cohort study of PN patients included in the Canadian Kidney Cancer information system (CKCis) database from January 2011 to January 2014. The $\mathrm{CKCis}$ has been collecting clinical and pathological data prospectively on all patients undergoing treatment for kidney cancer at 15 participating institutions across six Canadian provinces since January 2011. In addition, centres have added retrospective data on patients treated prior to 2011. Data is collected in a centralized server. All participating institutions have institutional review board approval and all patients have provided written consent to participate in the study. All patients who had a PN using open, laparoscopic, and robotic-assisted approaches to surgery were included.

\section{Data collection}

Baseline and clinical information was obtained from the medical record. Pathological reports were used to abstract tumour information, including tumour size, stage, and grade. If specifically described in the pathology report, PSM or NSM status was obtained. Patients where the margin status was not reported were excluded. Postoperative followup was not mandated, but generally followed the Canadian Urological Association guidelines ${ }^{17}$ for postoperative surveillance.

\section{Statistical analysis}

Baseline characteristics were summarized. To determine risk factors for a PSM, univariable and multivariable logistic regression analysis was performed. In the multivariable models, variables were included on a priori basis, to predict PSM, and disease progression based on patient and tumour characteristics. To calculate estimates of progression, patients without evidence of metastasis at the time of PN were included. Kaplan-Meier survival curves with 95\% confidence interval $(\mathrm{Cl})$ were used to estimate progressionfree survival (PFS) after PN. The log-rank test was used to compare the unadjusted PFS between the NSM and PSM groups. Cox proportional hazard was used to adjust for potential confounders of the association between surgical margin status and progression. All statistical analysis was done using $\mathrm{R}$ statistical environment. ${ }^{18} \mathrm{~A} p$ value of $5 \%$ or less was considered statistically significant.

\section{Results}

\section{Baseline characteristics}

Of 1103 patients, $972(88.1 \%)$ had NSM, 71 (6.4\%) had PSM, and 60 (5.4\%) had unknown status. Baseline patient characteristics of both PSM and NSM groups are summarized in Table 1. Both cohorts were very similar in most of the parameters, including tumour size, operative time, ischemia time, pathologic T stage, and Fuhrman grade. Estimated blood loss was significantly higher in the PSM group as compared to the NSM group ( $\mathrm{p}=0.02)$.

\section{Predictors of PSM}

On univariable analysis, blood loss, tumour grade, and tumour stage were associated with risk of a PSM (Table 1). On multivariable analysis adjusted for age, gender, surgical approach, tumour size, pathological T stage, and tumour grade, only pathological stage T3 or higher (odds ratio [OR] $2.51 ; 95 \% \mathrm{Cl} 1.13-5.60)$ and Fuhrman grade 4 (OR 5.35; 95\% CI 1.11-25.72) predicted the presence of a PSM (Table 2).

\section{Cancer recurrence and death}

To estimate progression and survival, 935 and 68 patients were eligible from the NSM and PSM groups, respectively. Forty-nine $(5.0 \%)$ patients (28 recurrences, 21 metastases) and seven $(9.9 \%)$ patients (two recurrences, five metastases) experienced cancer progression in the NSM and PSM groups, respectively. The unadjusted PFS was higher in patients with a NSM ( $p=0.025$; univariate Cox hazard ratio [HR] 2.4; 95\% Cl 1.08-5.32; Fig. 1). Adjusting for potential confounders, the association between a PSM and recurrence of disease was not statistically significant (adjusted HR 1.4; 95\% Cl 0.6, 3.6; $\mathrm{p}=0.48$; Table 3).

At a median followup of 19 (interquartile range [IQR] 5-42) and 15 (IQR 7-30) months, three cancer-related deaths occurred in the NSM cohort and no cancer-related deaths occurred in the PSM cohort. There were 13 deaths from any cause in the NSM group and one death in the PSM group. Eight hundred fifty-five (91.4\%) and 61 (89.7\%) patients were alive at last followup in the NSM and PSM groups, respectively.

\section{Discussion}

PN has established itself as the standard of care for small renal masses whenever technically feasible. In a prospective, randomized, European Organization for Research and 
Bansal et al.

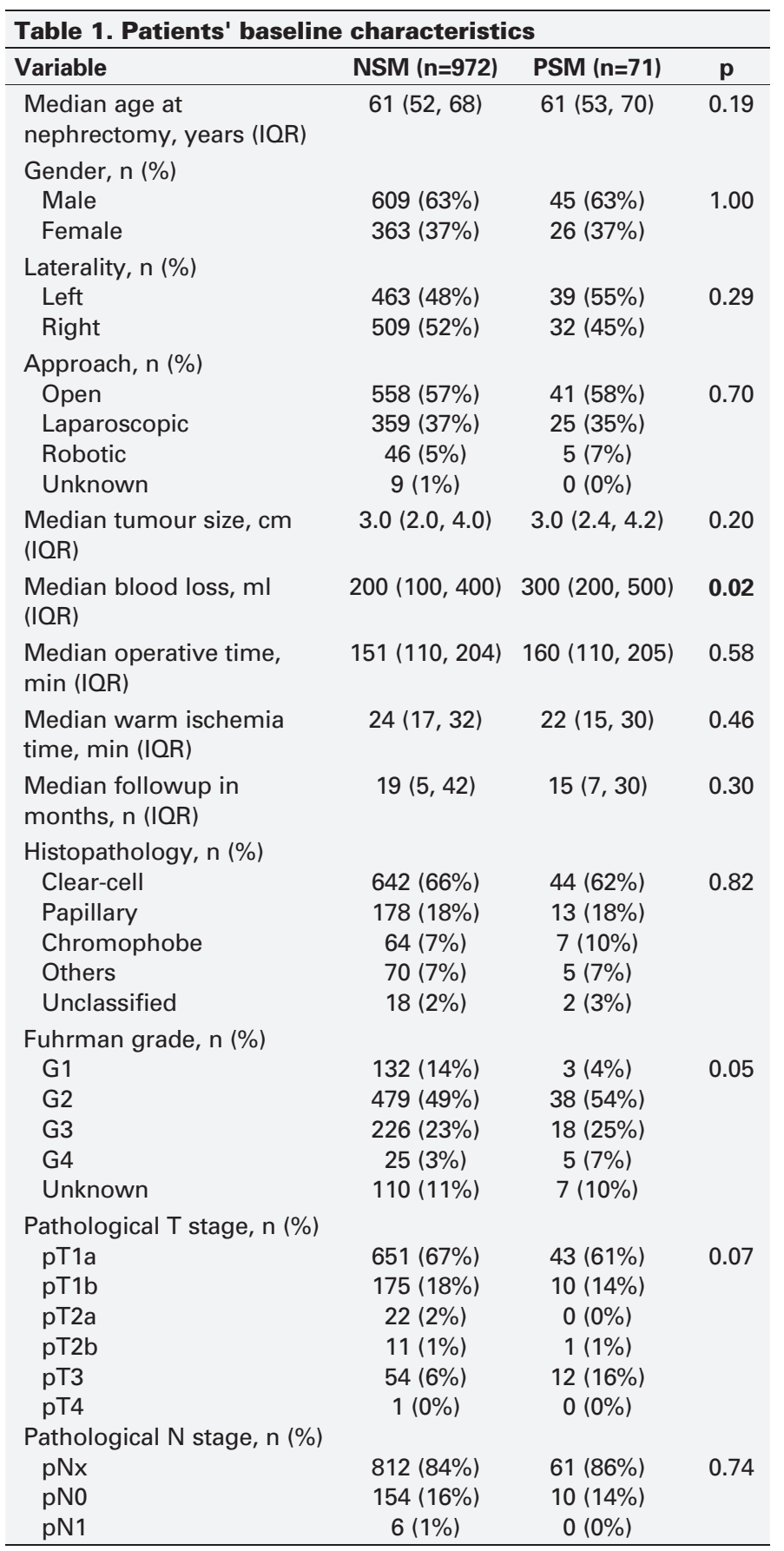

IQR: interquartile range; NSM: negative surgical margin; PSM: positive surgical margin.

Treatment of Cancer (EORTC) phase 3 study comparing nephron-sparing surgery and radical nephrectomy for renal masses measuring $5 \mathrm{~cm}$ or less, oncological outcomes were found to be similar in both groups, although a modest overall survival benefit was observed after radical nephrectomy. ${ }^{5}$ Other studies have also reported similar oncological outcomes between radical and PN. $6,7,8,19$

In the present study, incidence of PSM was $6.4 \%$, which is consistent with the results reported by many others in

\begin{tabular}{lcccc}
\hline \multicolumn{5}{l}{ Table 2. Predictors of PSM (multivariable regression) } \\
\hline Variable & OR & LCI & UCI & $\mathbf{p}$ \\
\hline Age at PN & 1.00 & 0.98 & 1.02 & 0.95 \\
$\quad$ Gender & & & & \\
$\quad$ Female (ref) & & & & \\
$\quad$ Male & 0.92 & 0.54 & 1.57 & 0.75 \\
Approach & & & & \\
$\quad$ Open (ref) & & & & \\
$\quad$ Laparoscopic & 1.00 & 0.57 & 1.77 & 1.00 \\
$\quad$ Robotic & 1.18 & 0.39 & 3.57 & 0.77 \\
Size of the tumour (cm) & 0.99 & 0.85 & 1.15 & 0.90 \\
Pathological T stage & & & & \\
$\quad$ T1 or T2 (ref) & & & & \\
$\quad$ T3 or T4 & 2.51 & 1.13 & 5.60 & $\mathbf{0 . 0 2}$ \\
Tumour grade & & & & \\
$\quad$ G1 (ref) & & & & \\
G2 & 2.94 & 0.88 & 9.83 & 0.08 \\
G3 & 2.87 & 0.81 & 10.17 & 0.10 \\
G4 & 5.35 & 1.11 & 25.72 & $\mathbf{0 . 0 4}$ \\
\hline
\end{tabular}

LCl: lower confidence interval; OR: odds ratio; PN: partial nephrectomy; UCl: upper confidence interval.

literature. The rate of PSM in various studies ranges from $0-18 \%$ and may be influenced by tumour size, tumour stage, fat invasion, imperative indication, solitary kidney, and surgical technique. ${ }^{10-12,16,20-26}$

Few studies have reported on the factors predicting PSM. Yossepowitch et al found association between decreasing tumour size and PSM. In their study, solitary kidney was associated with PSM, but it lost significance after adjust-

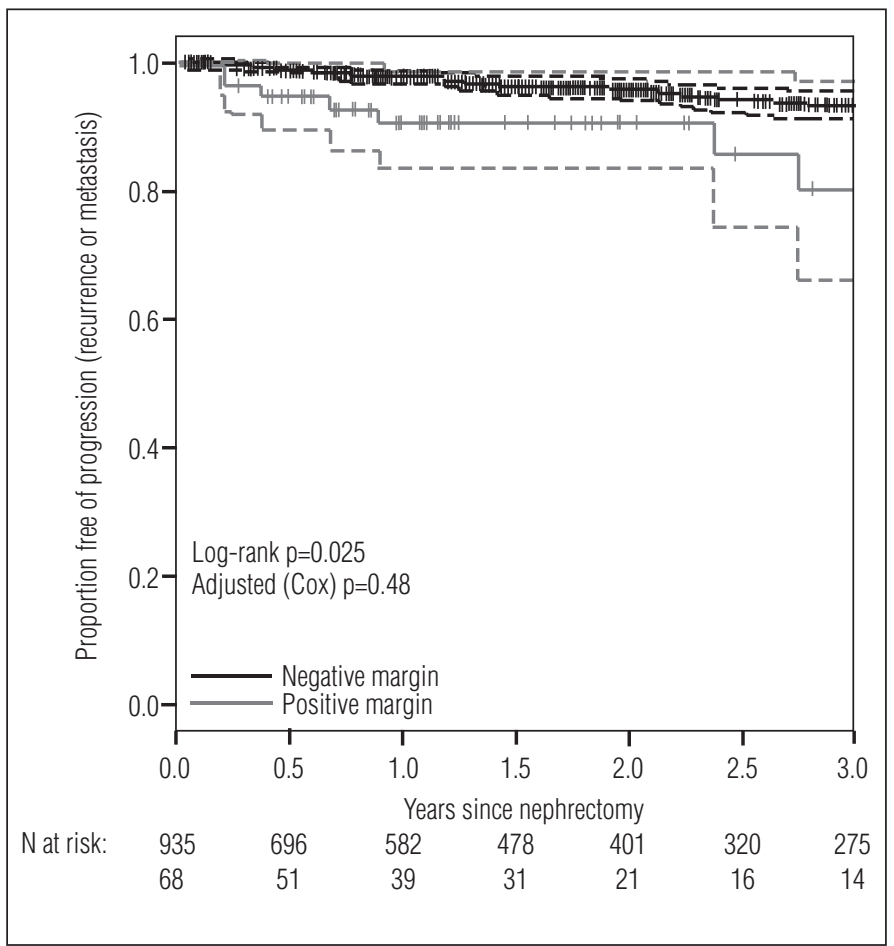

Fig. 1. Kaplan-Meier curve for progression-free survival. 


\begin{tabular}{|c|c|c|c|c|}
\hline Variable & HR & LCI & UCl & $\mathbf{p}$ \\
\hline \multicolumn{5}{|l|}{ Margin } \\
\hline \multicolumn{5}{|l|}{ Negative (ref) } \\
\hline Positive & 1.40 & 0.55 & 3.56 & 0.48 \\
\hline Age at PN & 1.03 & 1.00 & 1.05 & 0.06 \\
\hline \multicolumn{5}{|l|}{ Gender } \\
\hline Male & 1.24 & 0.68 & 2.25 & 0.49 \\
\hline \multicolumn{5}{|l|}{ Approach } \\
\hline \multicolumn{5}{|l|}{ Open (ref) } \\
\hline Laparoscopic & 1.03 & 0.55 & 1.94 & 0.93 \\
\hline Robotic & 0.82 & 0.11 & 6.22 & 0.85 \\
\hline Size of the tumour $(\mathrm{cm})$ & 1.31 & 1.19 & 1.44 & $<0.001$ \\
\hline \multicolumn{5}{|l|}{ Pathological T stage } \\
\hline $\mathrm{T} 3$ or $\mathrm{T} 4$ & 2.13 & 0.90 & 5.05 & 0.08 \\
\hline \multicolumn{5}{|l|}{ Tumour grade } \\
\hline \multicolumn{5}{|l|}{ G1 (ref) } \\
\hline $\mathrm{G} 2$ & 1.32 & 0.50 & 3.52 & 0.58 \\
\hline G3 & 1.28 & 0.44 & 3.66 & 0.65 \\
\hline G4 & 2.87 & 0.69 & 11.89 & 0.15 \\
\hline
\end{tabular}

ing for the tumour size..$^{21}$ In the present study, the association between presence of PSM and higher stage or grade of tumour may be explained by the fact that fat invasion is difficult to detect based on imaging or intraoperatively, and may increase the likelihood of PSM, as reported by Ani et al. ${ }^{10}$ Kwon et $\mathrm{al}^{12}$ found imperative indication of $\mathrm{PN}$ to be significant predictor of PSM, whereas Khalifeh et $\mathrm{al}^{16}$ did not find any risk factor for PSM among tumour size, pathological stage, grade, multiple tumours, growth pattern, and learning curve. It is important to note, however, that these studies (including the present study) are quite heterogeneous (i.e., they differed based on surgical expertise levels [e.g., residents, fellows and staff]; settings [e.g., community vs. academic] surgical techniques; era; etc.) and took different variables into account to determine predictors of PSM.

Presence of PSM on final histopathological examination creates uncertainty in terms of further management options. Many surgeons have performed completion radical nephrectomy or re-resection of the surgical margin when a PSM is found. In these studies, tumour is infrequently found in the re-resected specimen. ${ }^{13-15}$ Sundram et al reported 29 patients with PSM who underwent either completion nephrectomy $(n=8)$ or re-resection of surgical margin $(n=21) .{ }^{15}$ None of the nephrectomy specimen had residual tumour and only two re-resection specimens showed presence of cancer. They concluded that completion radical nephrectomy or re-resection is an overtreatment and clinical correlation is recommended to manage patients with PSM with consideration of impact on the residual renal function. Many others have placed the patients on stringent followup protocol to detect local and/or distant progression. Table 4 reviews the data on recurrence and metastasis in patients with PSM after PN. Many studies have found that PSM may not signify adverse prognosis for local or metastatic progression and therefore, of 1344 patients, Yossepowitch et al reported similar five- and 10-year local, as well as metastatic PFS for patients with PSM and NSM. ${ }^{21}$ They advocated that patients with PSM can be safely monitored without significant risk of recurrence. In a non-systematic review of the literature, Marszalek et al concluded that most patients with PSM after $\mathrm{PN}$ remain disease-free over intermediate-term followup and active surveillance is preferred over surgical reintervention. ${ }^{11}$ On the other hand, in a recent multi-institutional report on oncological outcomes of PSM after robot-assisted PN by Khalifeh et al, PSM on final pathological evaluation was found to be associated with increased likelihood of local recurrence, as well as metastasis. ${ }^{16}$ Of 21 patients with PSM, two $(9.5 \%)$ developed a local recurrence and two $(9.5 \%)$ developed metastasis, compared to seven $(0.7 \%)$ and two

\begin{tabular}{|c|c|c|c|c|c|}
\hline Authors & $\begin{array}{l}\text { Tumour size } \\
\text { (in cm) }\end{array}$ & Positive surgical margin rate & Followup & Recurrence & Metastasis \\
\hline Ani et al $^{10}$ & NA & $10.7 \%(71 / 664)$ & 7.9 years & NA & NA \\
\hline Kwon et $\mathrm{al}^{12}$ & 3.0 & $7 \%(57 / 770)$ & 22 months & $4 \%(2 / 57)$ & $4 \%(2 / 57)$ \\
\hline Lopez-Costea et al ${ }^{13}$ & 3.1 & $6.5 \%(9 / 137)$ & 80.5 months & 0 & 0 \\
\hline Raz et $\mathrm{al}^{14}$ & 2.9 & $15 \%(17 / 114)$ & 71 months & 0 & 0 \\
\hline Khalifeh et al ${ }^{16}$ & 2.9 & $2.2 \%(21 / 943)$ & 17.3 months & $9.5 \%(2 / 21)$ & $9.5 \%(2 / 21)$ \\
\hline Yossepowitch et al ${ }^{21}$ & 3.2 & $5.5 \%(77 / 1344)$ & 3.4 years & NA & NA \\
\hline Lee et $a^{22}$ & 3.2 & $16.6 \%(5 / 30)$ & 29 months & $40 \%(2 / 5)$ & NA \\
\hline Peycelon et $\mathrm{al}^{23}$ & 5.6 & $18 \%(11 / 61)$ & 70.7 months & $9 \%(1 / 11)$ & $18 \%(2 / 11)$ \\
\hline Sutherland et $\mathrm{a}^{24}$ & 3.2 & $7 \%(3 / 44)$ & 49 months & $33 \%(1 / 3)$ & $33 \%(1 / 3)$ \\
\hline Permpongsokol et a $\left.\right|^{25}$ & 2.8 & $1.8 \%(9 / 511)$ & 32 months & 0 & $11 \%(1 / 9)$ \\
\hline Desai et $\mathrm{al}^{26}$ & 2.2 & $10 \%(5 / 50)$ & 56.4 months & 0 & 0 \\
\hline Bansal et al (present study) & 3.0 & $6.4 \%(71 / 1103)$ & 15 months & $2.8 \%(2 / 71)$ & $7 \%(5 / 71)$ \\
\hline
\end{tabular}


Bansal et al.

$(0.2 \%)$ out of 922 patients with NSM over a mean followup of 17.3 months. Their findings definitely require further validation, as more reports on PSM continue to emerge; needless to say, NSM with complete excision of tumour remains the ultimate goal in all patients.

In the present study, estimated blood loss was significantly higher in the PSM group, which may signify potential complexity of the tumour and difficult surgery. More patients seem to have progressed from the PSM group (9.9\%) vs. NSM group $(5.0 \%)$, but three-year PFS was not significantly different in between groups and there was no cancer-specific mortality in the PSM group. This could also be explained by the premise that surgical margin status may not be as relevant in the small renal masses, but as we push the limits and do more larger and complex tumours, this relationship will need to be closely monitored (e.g., the PSM of a $7 \mathrm{~cm}$ tumour might be biologically more relevant that that of a $2.5 \mathrm{~cm}$ tumour). On the Cox proportional hazards model, only tumour size was significantly associated with disease progression (Table 3), whereas margin status, age, gender, approach, T stage, and tumour grade were not. We agree with the views expressed by many others that use of electrocautery/argon beam on the renal resection bed to achieve hemostasis before closure of the defect may lead to destruction of tumour cells at the margin, thus resulting in similar PFS. ${ }^{10,21}$

Potential limitations of this study include retrospective data collection, possible reporting bias, lack of central pathology review, and relatively short followup. The presented data did not have information on tumours in solitary kidneys, nor on bilateral and/or multifocal tumors. We did not have information as to whether some PSMs were managed with re-resection or completion nephrectomy. Our findings would also be strengthened if we had nephrometry data to assess the difficulty of the cases reported. One of the major strengths of this study is the fact that data was collected at multiple institutions across Canada and that procedures were performed by many surgeons (including fellows and residents with varying levels of experience) using different surgical techniques (e.g., open, laparoscopic, and robotic-assisted).

\section{Conclusion}

PSM was found in $6.4 \%$ of PNs performed for RCC in this cross-Canada, 1103-patient cohort. Risk factors for a PSM include pathological stage T3 or higher, higher tumour grade (Fuhrman 4), and higher intraoperative blood loss. A higher proportion of patients with a PSM had cancer progression, but this may be partially explained by differences in baseline risk. Given these findings, active surveillance seems to be a preferable approach over surgical intervention for management of PSM following PN for RCC. Intermediate- to longerterm followup is required to validate this recommendation.
Competing interests: Dr. Tanguay has been an advisor for Pfizer and has received a travel grant from Sanofi. Dr. Rendon has been an advisor and speaker for Amgen, Astellas, Ferring, and Janssen. Dr. Moore has been an advisor for Janssen and a speaker for GSK. Dr. Black has been an advisor for Abbvie, Amgen, Astellas, Biocancell, Cubist, Janssen, Novartis, and Sitka; a speaker for Abbvie, Janssen, Ferring, Novartis, and Red Leaf Medical; has received grants/honoraria from Pendopharm; has participated in clinical trials supported by Amgen, Astellas, Ferring, Janssen, and Roche; and has received research funding from GenomeDx, iProgen, Lilly, and New B Innovation. Dr. Kawakami has received travel grants from Baxter and Pentopharm. Dr. Drachenberg has been an advisor for Astellas and Janssen; a speaker for Actavis (formerly Watson) and Amgen; and has participated in clinical trails run by Cancer Care Manitoba (CCMB). Dr. Jewett has been an advisor for and received honoraria from Pfizer; and holds shares in Theralase Therapeutics. Dr. Kapoor has been an advisor and speaker for, and has participated in clinical trials supported by Amgen, Astellas, GSK, Janssen, Novartis, Pfizer, and Sanofi. The remaining authors report no competing personal or financial interests.

This paper has been peer-reviewed.

\section{References}

1. Jemal A, Siegel R, Xu J et al. Cancer statistics, 2010. CA Cancer J Clin 2010;60: 277-300. https://doi.org/10.3322/caac.20073

2. King SC, Pollack L, Li J, et al. Continued rise in incidence of renal cell carcinoma, especially in young patients and high-grade disease: United States 2001-2010. J Urol 2014;191:1665-70. https://doi.org/10.1016/i.juro.2013.12.046

3. Hollingsworth $J M$, Miller DC, Daignault S, et al. Rising incidence of small renal masses: A need to reassess treatment effect. J Natl Cancer Inst 2006;98:1331-4. https://doi.org/10.1093/inci/dij362

4. Volpe A, Cadeddu JA, Cestari A, et al. Contemporary management of small renal masses. Eur Urol 2011;60:501-15. https://doi.org/10.1016/i.eururo.2011.05.044

5. Van Poppel H, Da Pozzo L, Albrecht W, et al. A prospective randomized EORTC intergroup phase 3 study comparing the oncological outcome of elective nephron-sparing surgery and radical nephrectomy for lowstage renal cell carcinoma. Eur Urol 201 1;59:543-52. hitps://doi.org/10.1016/j.eururo.2010.12.013

6. Becker $F$, Siemer $S$, Humke $U$, et al. Elective nephron sparing surgery should become standard treatment for small unilateral renal cell carcinoma: Long-term survival data of 216 patients. Eur Urol 2006;49:30813. https://doi.org/10.1016/i.eururo.2005.10.020

7. Patard JJ, Shvarts 0 , Lam JS, et al. Safety and efficacy of partial nephrectomy for all $\mathrm{Tl}$ tumours based on an international multicentre experience. J Urol 2004;171:2181-5. https://doi.org/10.1097/01. ju.0000124846.37299.5e

8. Crepel $M$, Jeldres $C$, Sun $M$, et al. A population-based comparison of cancer-control rates between radical and partial nephrectomy for Tla renal cell carcinoma. Urology 2010;76:883-8. https://doi.org/10.1016/i.urology.2009.08.028

9. Borghesi $M$, Brunocilla $E$, Schiavina R, et al. Positive surgical margins after nephron-sparing surgery for renal cell carcinoma: Incidence, clinical impact, and management. Clinical Genitourinary Cancer 2013;1 1:5-9. https://doi.org/10.1016/i.llgc.2012.09.010

10. Ani I, Finelli A, Alibhai SMH, et al. Prevalence and impact on survival of positive surgical margins in partial nephrectomy for renal cell carcinoma: A population-based study. BJU Int 2013;111:E300-5. https://doi.org/10.1111/i.1464-410X.2012.11675.x

11. Marszalek M, Carini $M$, Chlosta $P$, et al. Positive surgical margins after nephron-sparing surgery. Eur Urol 2012;61:757-63. https://doi.org/10.1016/i.eururo.2011.11.028

12. Kwon E0, Carver BS, Snyder ME, et al. Impact of positive surgical margins in patients undergoing partial nephrectomy for renal cortical tumors. BJU Int 2006;99:286-9. https://doi.org/10.1111/i.1464410X.2006.06623.x

13. Lopez-Costea MA, Fumadó $L$, Lorente $D$, et al. Positive margins after nephron-sparing surgery for renal cell carcinoma: Long-term followup of patients on active surveillance. BJU Int 2010;106:645-8. htrps://doi.org/10.1111/i.1464-410X.2009.09174.x

14. Raz 0 , Mendlovic $S$, Shilo Y, et al. Positive surgical margins with renal cell carcinoma have a limited influence on long-term oncological outcomes of nephron-sparing surgery. Urology 2010;75:277-81. https://doi.org/10.1016/i.urology.2009.06.110

15. Sundaram V, Figenshau RS, Roytman $T M$, et al. Positive margin during partial nephrectomy: Does cancer remain in the renal remnant? Urology 2011;77:1400-3. https://doi.org/10.1016/i.urology.2010.12.016 


\section{${ }^{\circ} \mathrm{XGEVA}$ \\ (denosumab)}

\section{Indication and clinical use:}

- XGEVA is indicated for reducing the risk of developing skeletal-related events (SREs) in patients with bone metastases from breast cancer, prostate cancer, non-small cell lung cancer, and other solid tumours.

- Not indicated for reducing the risk of developing skeletal-related events in patients with multiple myeloma.

- Not indicated for reducing the risk of developing skeletal-related events in pediatric patients.

Contraindication:

- XGEVA is contraindicated in patients with pre-existing hypocalcemia, which must be corrected prior to initiating therapy.

\section{Most serious warnings and precautions:}

Osteonecrosis of the jaw (ONJ): In clinical trials, the incidence of ONJ was higher with longer duration of exposure. In patients with risk factors for $0 \mathrm{NJ}$, an individual risk/benefit assessment should be performed before initiating therapy with XGEVA. An oral exam should be performed and a dental exam with appropriate preventive dentistry is recommended prior to treatment with XGEVA, especially in patients with risk factors for ONJ. Avoid invasive dental procedures while receiving XGEVA. In patients who develop ONJ during treatment with XGEVA, a temporary interruption of treatment should be considered based on individual risk/benefit assessment until the condition resolves.

Other relevant warnings and precautions:

- Do not use concurrently with Prolia ${ }^{\circledR}$

- Do not use concurrently with bisphosphonates

- Hypocalcemia has been reported (including severe symptomatic hypocalcemia and fatal cases). Monitor calcium prior to the initia dose, within two weeks after the initial dose, and if suspected symptoms of hypocalcemia occur. Administer adequate calcium, vitamin $\mathrm{D}$, and magnesium, as necessary. If hypocalcemia occurs while receiving XGEVA, additional short-term calcium supplementation and additional monitoring may be necessary.

- Caution on risk of hypocalcemia and accompanying increases in parathyroid hormone in patients with renal impairment

- Clinically significant hypercalcemia has been reported in

XGEVA-treated patients with growing skeletons weeks to months following treatment discontinuation. Monitor patients for signs and symptoms of hypercalcemia and treat appropriately.

- Skin infections

- Hypersensitivity reactions including anaphylaxis

- Atypical femoral fractures

- Not recommended for use in pregnant women. Women should not become pregnant during treatment and for at least 5 months after the last dose of XGEVA.

- For nursing women, it is not known whether XGEVA is excreted into human milk.

\section{For more information:}

Please consult the Product Monograph at

http://www.amgen.ca/Xgeva_PM.pdf for important information relating to adverse reactions, drug interactions, and dosing that have not been discussed here.

The Product Monograph is also available by calling Amgen Medical Information at 1-866-502-6436.

\section{Fizazi et al. study ${ }^{2}$}

Phase 3, randomized, double-blind, double-dummy, active-controlled study. Patients with castrate-resistant prostate cancer and bone metastases $(n=1901)$ received either $120 \mathrm{mg}$ XGEVA ${ }^{\oplus}$ SC Q4W (once every 4 weeks) $(n=950)$ or 4 mg zoledronic acid IV Q4W $(n=951)$. The primary outcome measure was to demonstrate non-inferiority of time to first on-study SRE as compared to zoledronic acid. The secondary outcome measures were superiority of time to first on-study SRE and superiority of time to first and subsequent SREs. An SRE is defined as any of the following: pathologic fracture, radiation therapy to bone, surgery to bone or spinal cord compression.

References:

1. XGEVA ${ }^{\circledR}$ Product Monograph, Amgen Canada, 2016.

2. Fizazi $\mathrm{K}$ et al. Denosumab versus zoledronic acid for treatment of bone metastases in men with castration-resistant prostate cancer: a randomized, double-blind study. Lancet. 2011;377(9768):813-822.

\section{AMCEN}

(c) 2017 Amgen Canada Inc All rights reserved.

Oncology

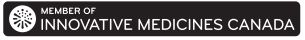

16. Khalifeh A, Kaouk JH, Bhayani S, et al. Positive surgical margins in robot-assisted partial nephrectomy: A multi-institutional analysis of oncological outcomes (leave no tumour behind). J Urol 2013;190:1674-9. https://doi.org/10.1016/i.juro.2013.05.110

17. Kassouf W, Siemens R, Morash, et al. Followup guidelines after radical or partial nephrectomy for localized and locally advanced renal cell carcinoma. Can Urol Assoc J 2009;3:73-6. https://doi.org/10.5489/ cuaj. 1028

18. R Core Team (2014). R: A language and environment for statistical computing. R Foundation for Statistical Computing, Vienna, Austria. Available at: http://www.R-project.org/. Accessed May 11, 2017.

19. Liungberg B. Nephron-sparing surgery strategy: The current standard for the treatment of localized renal cell carcinoma. Eur Urol 2011;10:e49-51. https://doi.org/10.1016/i.eursup.2011.03.003

20. Breda A, Stepanian SV, Liao J, et al. Positive margins in laparoscopic partial nephrectomy in 855 cases: A multi-institutional survey from the U.S. and Europe. J Urol 2007;178:47-50. https://doi.org/10.1016/i.juro.2007.03.045

21. Yossepowitch 0 , Thompson RH, Leibovich $B C$, et al. Positive surgical margins at partial nephrectomy: Predictors and oncological outcomes. J Urol 2008;179:2158-63. https://doi.org/10.1016/i. juro.2008.01.100

22. Lee DJ, Hruby G, Benson MC, et al. Renal function and oncologicl outcomes in nephron-sparing surgery for renal masses in solitary kidneys. World J Urol 2011;29:343-8. https://doi.org/10.1007/s00345010-0576-9

23. Peycelon $M$, Hupertan $V$, Comperat $E$, et al. Long-term outcomes after nephron-sparing surgery for renal cell carcinoma larger than $4 \mathrm{~cm}$. J Urol 2009; 181:35-41. https://doi.org/10.1016/i.juro.2008.09.025

24. Sutherland SE, Resnick MI, Maclennan GT, et al. Does the size of the surgical margin in partial nephrectomy for renal cell cancer really matter? J Urol 2002;167:61-4. https://doi.org/10.1016/S0022$5347(05) 65383-9$

25. Permpongkosol S, Colombo JR, Gill IS, et al. Positive surgical parenchymal margin after laparoscopic partial nephrectomy for renal cell carcinoma: Oncological outcomes. J Urol 2006;176:2401-4. https://doi.org/10.1016/i.juro.2006.08.008

26. Desai PJ, Andrew PE, Ferrigni RG, et al. Laparoscopic partial nephrectomy at the Mayo Clinic Arizona: Followup surveillance of positive margin disease. Urology 2008;71:283-6. https://doi.org/10.1016/i. urology.2007.08.050

Correspondence: Dr. Anil Kapoor, Division of Urology, McMaster University, Hamilton, ON, Canada; akapoor@mcmaster.ca 